\title{
The influence of diet on the exocrine pancreatic secretion of growing pigs
}

\author{
BY I. G. PARTRIDGE, A. G. LOW AND I. E. SAMBROOK \\ National Institute for Research in Dairying, Shinfield, Reading RG2 $9 A T$
}

AND T. CORRING

Centre National de Recherches Zootechniques - INRA, 78350 Jouy-en-Josas, France

(Received 22 June 1981-Accepted 4 January 1982)

\begin{abstract}
1. Pancreatic juice was collected from six pigs of $48 \mathrm{~kg}$ initial weight fitted with a collection catheter in the pancreatic duct and a return catheter in the duodenum.

2. Measurements of flow and composition of the juice were made during $24 \mathrm{~h}$ periods after adaptation to isonitrogenous diets based on barley, wheatings and fish meal (diet BWF) or starch, sucrose, casein, maize oil and cellulose (diet SSC), given in a change-over design. Measurements were also made during the periods of adaptation to a change from one diet to the other.

3. Mean flow-rates for pigs adapted to diets showed a highly significant four-fold difference between diets; values were $4962 \mathrm{ml} / \mathrm{d}$ for diet BWF and $1273 \mathrm{ml} / \mathrm{d}$ for diet SSC. The hourly volumes of juice were very variable and showed no clear response to feeding and no consistent diurnal pattern for either diet.

4. There were no significant differences between diets in the specific activities of the proteases. Average values were (units/mg protein) trypsin (EC 3.4.21.4) 29.6, chymotrypsin (EC 3.4.21.1) 7.7, carboxypeptidase A (EC 3.4.17.1) 0.65 , carboxypeptidase B (EC 3.4.17.2) $1 \cdot 6$. The total output of each tended to be higher with diet BWF than with diet SSC. The specific activities and total outputs of $\alpha$-amylase $(E C 3.2 .1 .1)$ and lipase (EC 3.1.1.3) were significantly higher for diet BWF than for diet SSC; specific activities for the two diets respectively were: (units/mg protein) $\alpha$-amylase 95.6 and 42.3 , lipase 59.0 and 14.5 .

5. The higher daily volume of juice with diet BWF was associated with significantly (but only slightly) higher levels of both sodium and potassium, compared with diet SSC.

6. The results are discussed in relation to previous studies on digestion at this Institute, in which pigs with intestinal cannulas were given the same diets.
\end{abstract}

The importance of pancreatic juice in the digestive processes of the growing pig has been emphasized by studies in which the pancreatic duct has been ligated. Corring \& Bourdon (1977) found that pigs with ligated pancreatic ducts grew at $421 \mathrm{~g} / \mathrm{d}$ compared with $560 \mathrm{~g} / \mathrm{d}$ for sham-operated controls. Ligation reduced the apparent digestibility of nitrogen by $35 \%$ and that of energy by $12 \%$. Similar results have been reported by Pekas et al. (1964) and by Anderson \& Ash (1971).

Chronic cannulation of the pancreatic duct has been used in several studies of pancreatic exocrine secretion in the pig. Pekas et al. (1966) studied the characteristics of secretion in pigs of 3-7 weeks of age. In older, growing pigs. Corring and his associates have made a number of studies including the secretory response to meal ingestion (Corring et al. 1972); the adaptation of secretion to different dietary protein levels (Corring \& Saucier, 1972); feedback regulation of pancreatic secretion (Corring, 1974) and the influence of duodenal loads of sugars (Corring \& Sumoes-Nunes, 1977).

One objective of the present study was to obtain further information on the influence of diet composition on the secretion of pancreatic juice and its components. The second objective was to resolve questions arising from previous work at Shinfield on digestive function in growing pigs. In recent years we have studied the processes of digestion and absorption by the technique of re-entrant cannulation at different sites in the small intestine. Reports have been published on the general characteristics of digesta flow and $\mathrm{pH}$ (Braude 
et al. 1976); the flow of dry matter (DM) ash and water (Low et al. 1978); the passage and absorption of individual mineral nutrients (Partridge, 1978a), nitrogen and amino acids (Low, 1979a, b), carbohydrates (Sambrook, 1979a), fibre and lipid (Sambrook, 1979b). Throughout this work it has been apparent that considerable difficulties of interpretation arise from the fact that the re-entrant cannulation technique does not allow differentiation between dietary and endogenous components of the digesta samples collected. In particular, duodenal digesta in our studies, as in most of those elsewhere, has included bile and pancreatic juice mixed with the gastric effluent. This is due to the difficulty of placing re-entrant cannulas anterior to the bile and pancreatic duct openings, which in the pig are approximately 40 and $100 \mathrm{~mm}$ respectively caudal to the pylorus. Therefore, studies were initiated on the quantitative and qualitative contributions of bile and pancreatic juice to the duodenal digesta. This account concerns only pancreatic secretion; our work on bile secretion has been reported elsewhere (Sambrook, 1981). The same diets were used in these studies as in the digestion studies cited previously and the results will be discussed in relation to our observations on duodenal digesta. A brief report of part of this work has been published previously (Partridge et al. 1979).

\section{EXPERIMENTAL}

Six pigs of $48 \mathrm{~kg}$, average initial live weight were prepared for complete collection and subsequent return of the pancreatic exocrine secretion, by the surgical procedure described by Corring et al. (1972). This involved the insertion of a polyethylene catheter into the pancreatic duct immediately above its point of entry into the duodenum. The duct was then tightly closed around the catheter by a suture. A second catheter was inserted into the duodenum, close to the normal point of entry of pancreatic juice. Both catheters were exteriorized through stab wounds in the flank. For a few days before surgery and during the recovery and experimental periods the pigs were kept in metabolism crates.

Throughout the trial, pancreatic juice was collected continuously by free drainage into a polyethylene bottle under ice. The juice was also returned continuously from a second container by means of a peristaltic pump. The pump was adjusted frequently so that the rate of juice return to the duodenum was similar to the rate of secretion.

Two isonitrogenous diets were compared: a practical growing pig diet based on barley, wheatings and fish meal (diet BWF) and a purified diet based on starch, sucrose and casein (diet SSC). The composition of these is given in Table 1. The average diet consumption during the experimental period was $1.6 \mathrm{~kg} / \mathrm{d}$. The animals were fed twice daily at 09.00 and 15.00 hours and the diet allowance was mixed with water just before feeding, allowing $2.51 / \mathrm{kg}$ diet. Each pig received both diets in a change-over design.

After recovering from surgery the animals were allowed a minimum of $5 \mathrm{~d}$ to become adapted to one or other of the test diets. Then flow rate was measured and samples were taken during two $24 \mathrm{~h}$ collections from each pig on consecutive days. Immediately following the second collection, each pig was abruptly changed onto the other test diet and two further consecutive 24 h collections were conducted, starting immediately, to monitor the changes in the characteristics of pancreatic secretion during the period of adaptation to the new diet. There were two further $24 \mathrm{~h}$ collections from each pig on days 5 and 6 following the diet change, when the pigs were deemed to have adapted to the new diet.

Collections started at 09.00 hours when the animals were given their morning feed. During the first collection from each pig when adapted to each of the diets, flow was measured and samples taken hourly throughout the $24 \mathrm{~h}$ period. For all remaining collections hourly measurements were recorded only until 21.00 hours, followed by a single measurement for the night period from 21.00 to 09.00 hours. At each of the stated times the juice collected in the bottle under ice was transferred to a measuring cylinder, the volume recorded and 
Table 1. Composition of experimental diets $(\mathrm{g} / \mathrm{kg})$

\begin{tabular}{|c|c|c|c|}
\hline \multicolumn{2}{|c|}{ Diet BWF } & \multicolumn{2}{|c|}{ Diet SSC } \\
\hline Barley meal & 712.5 & Maize starch & $612 \cdot 7$ \\
\hline Fine wheat offal & $200 \cdot 0$ & Sucrose & $100 \cdot 0$ \\
\hline White-fish meal & $70 \cdot 0$ & Maize oil & $30 \cdot 0$ \\
\hline $\mathrm{NaCl}$ & $2 \cdot 7$ & Cellulose & $30 \cdot 0$ \\
\hline $\mathrm{CaHPO}_{4} \cdot 2 \mathrm{H}_{2} \mathrm{O}$ & $5 \cdot 6$ & Casein & $184 \cdot 0$ \\
\hline $\mathrm{CaCO}_{3}$ & $6 \cdot 2$ & $\mathrm{CaHPO}_{4} \cdot 2 \mathrm{H}_{2} \mathrm{O}$ & 20.6 \\
\hline Vitamin supplement* & $2 \cdot 0$ & $\mathrm{CaCO}_{3}$ & $4 \cdot 6$ \\
\hline \multirow{2}{*}{$\mathrm{CuSO}_{4} \cdot 5 \mathrm{H}_{2} \mathrm{O}$} & 1.0 & $\mathrm{NaCl}$ & $5 \cdot 0$ \\
\hline & & $\begin{array}{l}\text { Vitamin and trace } \\
\text { mineral supplement }\end{array}$ & $13 \cdot 1$ \\
\hline
\end{tabular}

* For composition, see Braude et al. (1976).

Table 2. Substrates and conditions of analysis for the enzymes

\begin{tabular}{|c|c|c|c|}
\hline Enzyme & Substrate & Buffer & pH \\
\hline $\begin{array}{l}\text { Trypsin } \\
(E C 3.4 .21 .4)\end{array}$ & $\begin{array}{l}p \text {-Toluene-sulphonyl-L- } \\
\text { arginine methyl ester }\end{array}$ & Tris-HCl, $0.046 \mathrm{M}$ & $8 \cdot 1^{*}$ \\
\hline $\begin{array}{l}\text { Chymotrypsin } \\
(E C 3.4 .21 .1)\end{array}$ & $\begin{array}{l}\text { Benzoyl-L-tyrosine } \\
\text { ethyl ester }\end{array}$ & Tris- $\mathrm{HCl}, 0.08 \mathrm{~m}$ & $7 \cdot 8^{*}$ \\
\hline $\begin{array}{l}\text { Carboxypeptidase } A \\
(E C 3.4 .17 .1)\end{array}$ & Hippuryl-L-phenylalanine & Tris-HCl, $0.025 \mathrm{M}$ & $7 \cdot 5+$ \\
\hline $\begin{array}{l}\text { Carboxypeptidase B } \\
(E C 3.4 .17 .2)\end{array}$ & Hippuryl-L-arginine & Tris-HCl, 0.025 м & $7.65 \ddagger$ \\
\hline $\begin{array}{l}\alpha \text { Amylase } \\
(E C 3.2 .1 .1)\end{array}$ & Soluble starch & Phosphate, $0.02 \mathrm{M}$ & $6.9 \S$ \\
\hline $\begin{array}{l}\text { Lipase } \\
\text { (EC 3.1.1.3) }\end{array}$ & $\begin{array}{l}\text { Stabilized olive oil } \\
\text { emulsion }\end{array}$ & Tris- $\mathrm{HCl}, 0.20 \mathrm{M}$ & $7 \cdot 7 \|$ \\
\hline
\end{tabular}

a $50 \mathrm{ml} / 1$ sample taken. For each pig the samples were bulked to form three samples representative of the first $6 \mathrm{~h}$, second $6 \mathrm{~h}$ and last $12 \mathrm{~h}$ of each collection. These were stored at $4^{\circ}$ to await analysis. After each sampling the remaining pancreatic juice was transferred to the return vessel from which it was pumped into the duodenum.

Each of the three composite samples of juice from each $24 \mathrm{~h}$ collection was analysed. With the exception of cation determinations which were done later on thawed samples, all measurements were done on fresh samples and were completed within $8 \mathrm{~h}$ of the end of the collection. Total protein was measured by the method of Lowry $e$ t al. (1951) and total $\mathrm{N}$ by the Kjeldahl method. Enzyme activities were measured by the procedures summarized in Table 2. For each enzyme, one unit of activity was defined as that which hydrolysed one $\mu \mathrm{mol}$ substrate $/ \mathrm{min}$ per $\mathrm{mg}$ protein at $25^{\circ}$. The bicarbonate concentration was determined by boiling briefly with an excess of $0 \cdot 1 \mathrm{M}$-hydrochloric acid and titrating the excess acid with $0.1 \mathrm{M}$-sodium hydroxide using phenolphthalein to determine the end-point. A silver electrode chloride meter (Evans Electroselenium Ltd) was used to measure chloride. Measurements of sodium and potassium were by flame emission and of calcium and magnesium by atomic absorption spectroscopy, performed on appropriate dilutions of the juice. 
RESULTS

Considerable practical difficulties were encountered during the course of this trial. Only three pigs completed all planned collections, due to the premature loss of the pancreatic duct catheter from the remaining animals. Additional pigs were prepared but these were even less successful. This low rate of success at Shinfield is difficult to explain in view of the fact that one of the authors (T. Corring) has had consistent success with pigs prepared in a similar way at Jouy-en-Josas.

In the main, the results presented here concern the two $24 \mathrm{~h}$ collections planned with each of the six pigs after adaptation to each of the two diets. Eight of the twenty-four values (four for each diet) were missing and calculated values were inserted in the analyses of variance.

To summarize the results for collections during the periods of adaptation to diet changes, within $48 \mathrm{~h}$ the pigs appeared to be fully adapted to a change from diet BWF to diet SSC and were almost completely adapted to a change from diet SSC to diet BWF, in terms of flow-rate. For example, one pig when adapted to diet BWF produced $5598 \mathrm{ml}$ juice/d; when changed abruptly to diet SSC the daily volumes were 3298,1362 and $1396 \mathrm{ml}$ for days 1 , 2 and 5 respectively. Another pig initially adapted to diet SSC produced $1686 \mathrm{ml}$ juice/d; when changed to diet BWF the daily volumes were 1930,3881 and $5056 \mathrm{ml}$ for days 1,2 and 5 respectively. Values for individual components of the juice were very variable but in general these too showed a marked adaptation within $2 \mathrm{~d}$ of a change in diet.

There appeared to be no consistent differences in juice composition between the samples representing the three parts of the $24 \mathrm{~h}$ collections. The results were therefore combined to give single $24 \mathrm{~h}$ values for each constituent.

\section{The flow of pancreatic juice}

Mean values for the volume of pancreatic juice secreted in $24 \mathrm{~h}$ by pigs adapted to each of the two diets are given in Table 3 . These results show that the volume with diet BWF was some four times that with diet SSC. Individual results within diets were quite variable but nevertheless the difference was highly significant. The mean hourly volumes of juice are shown in Fig. 1; individual values showed considerable variability and there was no clear response to feeding and no consistent diurnal pattern.

\section{Enzyme composition}

Mean values for the total protein content of the juice and the specific activities of the pancreatic enzymes are given in Table 3. Values for total $\mathbf{N}$ are also given to allow comparison with previous measurements in duodenal digesta. On average, the total weight of secreted protein was approximately $45 \%$ higher with diet BWF than with diet SSC. However, the individual values were very variable and the difference was not statistically significant. The specific activity values for each of the proteases and peptidases were very similar for the two diets. However, since there was a tendency for higher total protein secretion with diet BWF there was a tendency also for higher total outputs of the enzymes with this diet. The total outputs of amylase and lipase were considerably higher with diet BWF than with diet SSC due to the combined effects of significantly higher specific activities and the trend for higher total protein secretion.

\section{Electrolyte composition}

The anion and cation concentrations are given in Table 3. For both diets $\mathrm{HCO}_{3}{ }^{-}$was the predominant anion but with diet $\mathrm{BWF}$ the $\mathrm{HCO}_{3}^{-}: \mathrm{Cl}^{-}$value was significantly higher than with diet SSC. The concentrations of both $\mathrm{Na}$ and $\mathrm{K}$ were slightly, but significantly, higher with diet BWF than with diet SSC; for Ca and $\mathrm{Mg}$, which made only small contributions 
Table 3. Flow and composition of pancreatic juice in $24 \mathrm{~h}$ collections from six pigs adapted to diets $B W F$ and $S S C \dagger$ in a change-over design

(Mean values for two collections from each pig on each diet, and the standard error of the difference (SED) between diet means: missing values were calculated for eight of the twenty-four plots)

\begin{tabular}{|c|c|c|c|}
\hline & Diet BWF & Diet SSC & $\operatorname{SED}(2 \mathrm{~d})$ \\
\hline Total flow $(\mathrm{ml})$ & 4962 & 1273 & $182 \cdot 6^{* *}$ \\
\hline Total protein $(\mathrm{g})$ & 9.8 & 6.7 & $2.45 \mathrm{NS}$ \\
\hline Total nitrogen $(\mathrm{g})$ & $2 \cdot 3$ & $1 \cdot 3$ & $0.39 \mathrm{NS}$ \\
\hline \multicolumn{4}{|c|}{ Enzyme specific activities (units/mg protein) } \\
\hline $\begin{array}{l}\text { Trypsin } \\
(E C 3.4 .21 .4)\end{array}$ & $32 \cdot 0$ & $27 \cdot 1$ & $2 \cdot 55 \mathrm{NS}$ \\
\hline $\begin{array}{l}\text { Chymotrypsin } \\
(E C 3.4 .21 .1)\end{array}$ & $7 \cdot 6$ & $7 \cdot 8$ & $2 \cdot 69 \mathrm{NS}$ \\
\hline $\begin{array}{l}\text { Carboxypeptidase A } \\
(E C 3.4 .17 .1)\end{array}$ & 0.6 & 0.7 & $0 \cdot 21 \mathrm{NS}$ \\
\hline $\begin{array}{l}\text { Carboxypeptidase B } \\
(E C 3.4 .17 .2)\end{array}$ & $1 \cdot 7$ & $1 \cdot 5$ & $0.38 \mathrm{NS}$ \\
\hline $\begin{array}{l}\text { Amylase } \\
(E C 3.2 .1 .1)\end{array}$ & $95 \cdot 6$ & $42 \cdot 3$ & $1.91 * * *$ \\
\hline $\begin{array}{l}\text { Lipase } \\
(E C \text { 3.1.1.3) }\end{array}$ & $59 \cdot 0$ & $14 \cdot 5$ & $12 \cdot 68^{*}$ \\
\hline \multicolumn{4}{|c|}{ Electrolyte composition (mmol/l) } \\
\hline Chloride & $19 \cdot 1$ & 33.9 & $4 \cdot 16^{*}$ \\
\hline Bicarbonate & 137.7 & $122 \cdot 6$ & $3 \cdot 32^{*}$ \\
\hline Sodium & $161 \cdot 1$ & $156 \cdot 3$ & $0.93^{*}$ \\
\hline Potassium & 5.0 & $4 \cdot 5$ & $0 \cdot 16^{*}$ \\
\hline Calcium & 0.45 & 0.7 & $0.11 \mathrm{NS}$ \\
\hline Magnesium & $0 \cdot 1$ & 0.2 & $0.03^{*}$ \\
\hline
\end{tabular}

NS, not significant.

- $P<0.05, * * P<0.01, * * * P<0.001$.

$\dagger$ For details of diets, see Table 1.

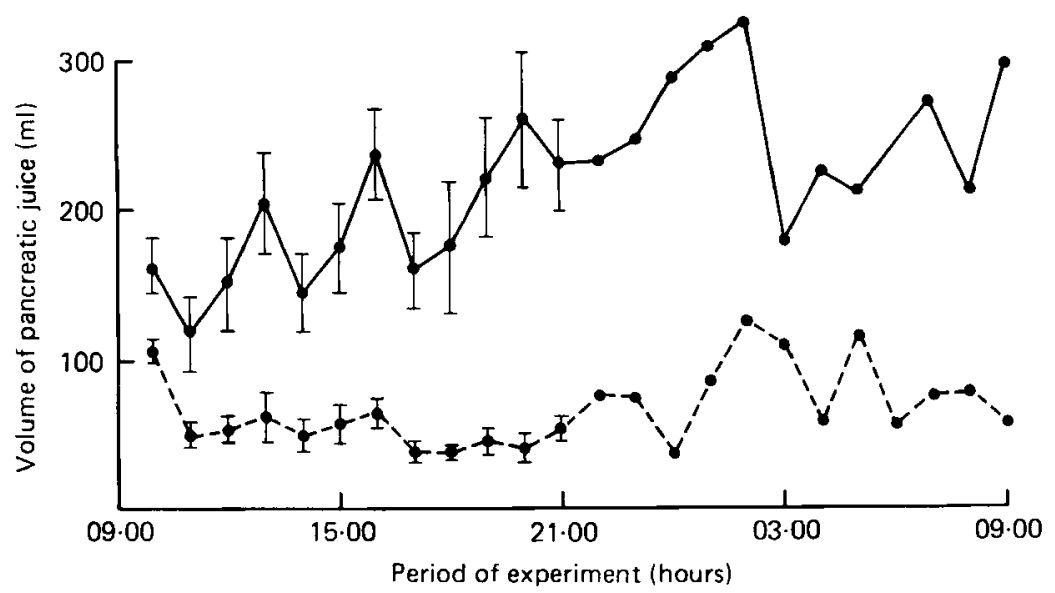

Fig. 1. Hourly pattern of pancreatic juice flow according to diet composition: (-) diet BWF; (---) diet SSC (for details of diet, see Table 1). From 10.00 until 21.00 hours values are means of eight collections with their standard errors represented by vertical bars. From 22.00 until 09.00 hours values are means of two collections. The pigs were fed at 09.00 and 15.00 hours. 
to the total cation concentration, the situation was reversed. The difference between diet means for Ca just failed to reach significance $(0 \cdot 10>P>0.05)$. The total amount of each electrolyte secreted was greater for diet BWF than for diet SSC by virtue of the greater volume of juice produced.

\section{DISCUSSION}

\section{Volume and flow pattern of pancreatic juice}

Corring (1980) reported that the average volume of pancreatic juice secreted in $24 \mathrm{~h}$ was 2.51 for pigs of $45 \mathrm{~kg}$ live weight given a cereal diet. In the present study the volumes secreted by $48 \mathrm{~kg}$ pigs were approximately twice this value for a cereal diet (diet BWF) and half for a purified diet (diet SSC). In a recent study by Zebrowska et al. (1981) pancreatic juice was collected from $40 \mathrm{~kg}$ pigs prepared with short pouches of duodenum into which the pancreatic duct opened; daily volumes were 2.21 for a cereal diet and 1.21 for a purified diet. Their purified diet was very similar in composition to diet SSC and, indeed, both induced similar volumes of pancreatic juice. However, their cereal diet was based on barley and soya-bean meal in contrast to diet BWF (barley, wheatings and fish meal). Although in comparing these studies the effects of pig weight and collection technique are confounded with diet effects, it is evident that diet composition can have a marked effect on the daily volume of pancreatic juice secreted.

It is of interest to consider the volume of pancreatic juice in relation to those of duodenal digesta and bile, which have been studied in previous work at this Institute, using the same diets. In pigs with re-entrant duodenal cannulas, the flow of water through the duodenum in $24 \mathrm{~h}$ was $11 \cdot 11$ and $7 \cdot 11$ more than was ingested, for diets BWF and SSC respectively; DM flow was similar to intake (Low et al. 1978). The present results show that pancreatic juice contributed approximately 45 and $18 \%$ of these volumes of endogenous fluid, for diets BWF and SSC respectively. Studies reported by Sambrook (1981) showed that bile secretion in $40 \mathrm{~kg}$ pigs amounted to $1.7 \mathrm{l} / \mathrm{d}$ for diet BWF and $1.2 \mathrm{l} / \mathrm{d}$ for diet SSC. By difference, it can be calculated that the combined volume of saliva and gastric juice was similar for both diets at approximately $4.5 \mathrm{l} / \mathrm{d}$. This value is of course nett of any reabsorption which may have occurred anterior to the proximal duodenum.

It was suggested by Low et al. (1978) that the differences in the water content of digesta in the duodenum, jejunum and ileum, and in faeces, were due to the higher fibre content of diet BWF (72 g acid-detergent fibre (ADF)/ $\mathrm{kg}$ ) compared with diet SSC (30 g ADF $/ \mathrm{kg}$ ). It is well known that dietary fibre increases intestinal water space in the pig (Cooper \& Tyler, 1959; Farrell \& Johnson, 1970; Partridge, 1978 b). The present results and those of Sambrook (1981) suggest that the effects of fibre may be mediated through increased secretion of pancreatic juice and bile.

In agreement with the work reviewed by Corring (1980) the present results show that the secretion of pancreatic juice is continuous in the pig (Fig. 1). Corring et al. (1972) reported that pigs responded to feeding by increasing pancreatic juice protein secretion, which reached a maximum approximately $3 \mathrm{~h}$ after feeding; in some pigs this was achieved by increased protein concentration in the juice while in others there was an increase in hourly volume. In the present trial there appeared to be no increase in flow-rate after feeding with either diet; protein content of the juice was not measured on an hourly basis.

The daily secretion of total $\mathrm{N}$ in pancreatic juice was $2.3 \mathrm{~g}$ for diet BWF and $1.3 \mathrm{~g}$ for diet SSC. These amounts represent approximately 5.8 and $3.2 \%$ respectively of the total daily $\mathrm{N}$ throughput in the duodenum of cannulated pigs given similar amounts of the same diets in a previous study (Low, 1979a). 
Enzyme content of pancreatic juice

The diets used differed considerably in their physical form; although their total protein content was similar, the types of protein differed: diet BWF contained a very wide variety of proteins while diet SSC contained only the relatively homogenous casein. These differences in protein type did not, however, lead to any significant change in the proportions of proteases or peptidases secreted. This observation was also made in pigs given similar diets by Zebrowska et al. (1981) in studies on pancreatic secretion, and by Low (1982) in studies on duodenal digesta. In common with the present study, the measurements of pancreatic proteases and peptidases were highly variable; the fact that this was found in three separate studies using different techniques suggests that this variability is a biological fact rather than a problem of analytical technique.

The proportions of chymotrypsin and trypsin secreted were similar to those found in pancreatic juice by Corring et al. (1972), and in duodenal digesta by Low (1982). However, the total amounts of activity differed between these three studies, probably due to differences in the level of feeding, diet composition or method of study.

The secretion of carboxypeptidases $\mathbf{A}$ and $\mathbf{B}$ found is generally similar to that obtained by Zebrowska et al. (1981), both in terms of total activity and proportions. In both studies carboxypeptidase A activity was less than half that of carboxypeptidase B, irrespective of diet.

The results of the present study indicate that synthesis and secretion of proteases greatly exceeds the amount which is theoretically required to hydrolyse dietary proteins.

Values for $\alpha$-amylase and lipase showed an effect of diet on both specific and total activities. In the case of $\alpha$-amylase, the results of the present study do not appear to agree with those of Corring (1980) who has shown that the secretion of an enzyme increases in response to an increased intake of its particular substrate: diet SSC in this study had a slightly higher content of starch than diet BWF but produced a lower secretion of $\alpha$-amylase. However, the starch in diet SSC was purified maize starch, which is more readily digested and absorbed in the small intestine (Sambrook, 1979 $a$ ) and produces a more pronounced blood glucose peak after feeding (Leeds et al. 1980) than the cereal starch in diet BWF. It may be that the more rapid release of starch hydrolysis products for diet SSC was responsible for the reduction in pancreatic $\alpha$-amylase secretion for this diet.

It is more difficult to account for the reduced lipase secretion with diet SSC compared with diet BWF. Although diet BWF contained $25 \%$ more lipid than diet SSC, the lipid in the latter diet was in the form of pure maize oil which is better digested and absorbed in the small intestine than the lipid in the cereal diet (Sambrook, 1979b).

\section{Electrolyte content of pancreatic juice}

There appear to be no previous reports on the electrolyte content of pancreatic juice measured in conscious pigs under normal physiological conditions. Hickson (1970) reported that in anaesthetized pigs in which pancreatic secretion was stimulated by secretin injection or by vagal stimulation, $\mathrm{HCO}_{3}{ }^{-}$concentration rose from $20-30 \mathrm{mmol} / \mathrm{l}$ in resting juice to 130-160 mmol/l when a higher flow-rate was induced. $\mathrm{Cl}^{-}$concentration responded in a reciprocal way, changing from $130 \mathrm{mmol} / \mathrm{l}$ in resting juice to $18-24 \mathrm{mmol} / \mathrm{l}$ at higher flow-rates. Similar responses to increasing flow-rate have been observed in other species (Janowitz, 1967). In the present study the same relationship was seen; the higher flow-rate associated with diet BWF, compared with diet SSC, was accompanied by a higher $\mathrm{HCO}_{3}$ and lower $\mathrm{Cl}^{-}$concentration. However, in this trial the values for both diets were comparable with those for the higher rates of flow in anaesthetized pigs. It is not possible to compare flow-rates directly as those of Hickson (1970) were reported as $\mu \mathrm{l} / \mathrm{g}$ pancreas per min. 
The higher $\mathrm{HCO}_{3}{ }^{-}$content of pancreatic juice coupled with the higher flow-rate in pigs given diet BWF resulted in a marked increase in the total buffering capacity in comparison with diet SSC. Average values for the daily secretion of bicarbonate were 683 and $156 \mathrm{mmol}$ for diets BWF and SSC respectively. In spite of this, previous measurements of the $\mathrm{pH}$ of duodenal digesta collected posterior to the pancreatic duct showed that digesta resulting from diet BWF was more acidic than that from diet SSC; average values over $24 \mathrm{~h}$ were 4.4 and 4.9 respectively (Braude et al. 1976). These results suggest that there was a much greater secretion of gastric acid with diet BWF.

The concentrations of $\mathrm{Na}$ and $\mathrm{K}$ in the present trial were similar to values for the anaesthetized pigs of Hickson (1970), who further reported that their concentrations did not change with increasing flow-rate induced by secretin or by vagal stimulation. The concentrations of both $\mathrm{Na}$ and $\mathrm{K}$ were significantly higher with diet BWF than with diet SSC but the difference was small numerically.

The total daily output of $\mathrm{Na}$ in pancreatic juice was $18.4 \mathrm{~g}$ for diet $\mathrm{BWF}$ and $4.6 \mathrm{~g}$ for diet SSC. Partridge (1978 a) reported that for pigs of similar weight given similar amounts of diet BWF and SSC the daily throughput of $\mathrm{Na}$ in the duodenum exceeded intake by 21.6 and $13.4 \mathrm{~g}$ respectively for the two diets. Thus pancreatic juice accounted for a large proportion of the endogenous $\mathrm{Na}$ and for a large part of the dietary difference. The previous duodenal studies also showed a daily net secretion of $\mathrm{K}$ of $3.1 \mathrm{~g}$ for diet BWF and $2.6 \mathrm{~g}$ for diet SSC; the present results show that pancreatic juice accounted for 1.0 and $0.2 \mathrm{~g} \mathrm{~K} / \mathrm{d}$ for the respective diets.

The $\mathrm{Ca}$ and $\mathrm{Mg}$ contents of pancreatic juice were relatively small. For these, duodenal throughput was very similar to intake in our previous work (Partridge, 1978a). The reason for the significant difference between diets in the $\mathrm{Mg}$ concentration in pancreatic juice is not readily apparent. The higher concentration of $\mathrm{Mg}$ and the tendency for a higher concentration of $\mathrm{Ca}$ with diet SSC may simply reflect the lower flow rate, compared with diet BWF. However, the total daily output of each of these elements was still considerably higher for diet BWF.

\section{REFERENCES}

Anderson, D. M. \& Ash, R. W. (1971). Proc. Nutr. Soc. 30, 34A.

Bernfield, P. (1951). Adv. Enzym. 12, 379.

Braude, R., Fulford, R. \& Low, A. G. (1976). Br. J. Nutr. 36, 497.

Cooper, P. H. \& Tyler, C. (1959). J. agric. Sci., Camb. 52, 332.

Corring, T. (1974). Annls Biol. anim. Biochim. Biophys. 14, 487.

Corring, T. (1980). In Current Concepts of Digestion and Absorption in Pigs, p. 136 [A. G. Low and I. G. Partridge, editors]. Reading: National Institute for Research in Dairying.

Corring, T., Aumaitre, A. \& Rerat, A. (1972). Annls Biol. anim. Biochim. Biophys. 12, 109.

Corring, T. \& Bourdon, D. (1977). J. Nutr. $107,1216$.

Corring, T. \& Saucier, R. (1972). Annls Biol. anim. Biochim. Biophys. 12, 233.

Corring, T. \& Sumoes-Nunes, C. (1977). Irish J. med. Sci. 146, Suppl 1, 43.

Farrell, D. J. \& Johnson, K. A. (1970). Anim. Prod. 14, 209.

Folk, J. E., Piez, K. A., Carroll, W. R. \& Gladner, J. A. (1960). J. biol. Chem. 235, 2272.

Folk, J. E. \& Schirmer, E. W. (1963). J. biol. Chem. 238, 3884.

Hickson, J. C. D. (1970). J. Physiol., Lond. 206, 275.

Hummel, B. C. W. (1959). Can. J. Biochem. Physiol. 37, 1303.

Janowitz, H. D. (1967). In Handbook of Physiology, Section 6, The Alimentary Canal, vol. 2, p. 925 [C. F. Code, editor]. Washington: The American Physiological Society.

Leeds, A. R., Kang, S. S., Low, A. G. \& Sambrook, I. E. (1980). Proc. Nutr. Soc. 39, 44A.

Low, A. G. (1979a). Br. J. Nutr. 41, 137.

Low, A. G. (1979b). Br. J. Nutr. 41, 147.

Low, A. G. (1982). Br. J. Nutr. 48, 147.

Low, A. G., Partridge, I. G. \& Sambrook, I. E. (1978). Br. J. Nutr. 39, 515.

Lowry, O. H., Rosenbrough, N. J., Farr, A. L. \& Randall, R. J. (1951). J. biol. Chem. 193, 265.

Partridge, I. G. (1978a). Br. J. Nutr. 39, 527.

Partridge, I. G. (1978b). Br. J. Nutr. 39, 539. 
Partridge, I. G., Low, A. G., Sambrook, I. E. \& Corring, T. (1979). Anim. Prod. 28, 440.

Pekas, J. C., Hays, V. W. \& Thompson, A. M. (1964). J. Nutr. 82, 277.

Pekas, J. C., Thompson, A. M. \& Hays, V. W. (1966). J. Anim. Sci. 25, 113.

Sambrook, I. E. (1979a). Br. J. Nutr. 42, 267.

Sambrook, I. E. (1979b). Br. J. Nutr. 42, 279.

Sambrook, I. E. (1981). J. Sci. Fd Agric. 32, 781.

Tietz, N. W. \& Fiereck, E. A. (1966). Clinica. chim. Acta 13, 352.

Zebrowska, T., Low, A. G. \& Zebrowska, H. (1981). Proc. Vlth int Symp. Amino Acids, Serock, Poland. 